Ross, CA; Aylward, EH; Wild, EJ; Langbehn, DR; Long, JD; Warner, JH; .. Tabrizi, SJ; + view all (2014) Huntington disease: natural history, biomarkers and prospects for therapeutics. Nature Reviews Neurology , 10 204- 216. 10.1038/nrneurol.2014.24.

\title{
Huntington disease: natural history, biomarkers and prospects for therapeutics
}

Christopher A. Ross, Elizabeth H. Aylward, Edward J. Wild, Douglas R. Langbehn, Jeffrey D. Long, John H. Warner, Rachael I. Scahill, Blair R. Leavitt, Julie C. Stout, Jane S. Paulsen, Ralf Reilmann, Paul G. Unschuld, Alice R. Wexler, Russell L. Margolis and Sarah J. Tabrizi

\begin{abstract}
Huntington disease (HD) can be seen as a model neurodegenerative disorder, in that it is caused by a single genetic mutation and is amenable to predictive genetic testing, and estimation of years to predicted onset, enabling the entire range of disease natural history to be studied. Structural neuroimaging biomarkers show that progressive regional brain atrophy begins many years before the emergence of diagnosable signs and symptoms of HD, and continues steadily during the symptomatic or 'manifest' period. The continued development of functional, neurochemical and other biomarkers are now in development, raises hopes that these biomarkers may be useful for future trials of disease-modifying therapeutics--ie to delay the onset and slow the progression of HD. Such advances could herald a new era of personalized preventive therapeutics in HD. In this Review, we describe the natural history of $\mathrm{HD}$, including the timing of emergence of motor, cognitive and emotional impairments, and the techniques that are used to assess these features. Building on this information, we also review recent progress in the development of biomarkers for HD, and the potential future roles of these biomarkers in clinical trials.
\end{abstract}

- Division of Neurobiology, Department of Psychiatry, Departments of Neurology, Neuroscience and Pharmacology, and Program in Cellular and Molecular Medicine, Johns Hopkins University, Baltimore MD 21218, USA. (C. A. Ross).

- Center for Integrative Brain Research, Seattle Children's Research Institute, 4800 Sand Point Way, NE Seattle, WA 98105, USA. (E. H. Aylward).

- C/o Box 104, Department of Neurodegenerative disease, Institute of Neurology, University College London, Queen Square, WC1N 3BG, London, UK. (E. J. Wild, R. I. Scahill, S. J. Tabrizi).

- Division of Neuropsychology, Departments of Psychiatry and Biostatistics, 200 Hawkins Drive, Carver College of Medicine, University of lowa, lowa City, IA 52242, lowa USA. (D. R. Langbehn, J. D. Long).

- CHDI Management/CHDI Foundation, 155 Village Boulevard, Suite 200, Princeton, New Jersey, 08540,USA. (J. H. Warner).

- Center for Molecular Medicine and Therapeutics, University of British Columbia, $95028^{\text {th }}$ Avenue W, Vancouver, British Columbia V5Z4H4, Canada. (B. R. Leavitt).

- School of Psychology and Psychiatry, Clinical and Cognitive Neuroscience laboratory, Monash University, Building 17, Clayton Campus, Wellington Road, Victoria 3800, Australia. (J. C. Stout).

- Division of Neuropsychology, Departments of Psychiatry and Biostatistics, 200 Hawkins Drive, Carver College of Medicine, University of lowa, lowa City, IA 52242, lowa USA. (J. S. Paulsen).

- George-Huntington-Institute Technologiepark Münster, Johann-Krane-Weg 27, 48149 Münster, Germany \& Department of Neurology, Albert-Schweitzer-Campus 1, Gebäude A 1 University of Muenster, 48149 Münster, Germany. (R. Reilmann). 
- Division of Psychiatric Research and Psychogeriatric Medicine, Department of Psychiatry, University of Zürich, Wagistrasse 12, 8952 Schlieren, Switzerland. (P. G. Unschuld).

- Center for the Study of Women UCLA Los Angeles, Box 957222, CA 90095-7222, California,USA. (A. R. Wexler).

- Division of Neurobiology, Department of Psychiatry, and Department of Neurology, and Program in Cellular and Molecular Medicine, Johns Hopkins University, Baltimore MD 21218, USA. (R. L. Margolis).

○

Correspondence to:

Christopher. A. Ross

caross@jhu.edu

Competing interests

The authors declare no competing interests.

Key points

- There are currently no disease-modifying treatments available for Huntington's disease (HD) but clinical trials of potential compounds are imminent; identifying suitable biomarkers to assess therapeutic efficacy is consequently a main priority in HD research.

- Quantifiable measures of patient function including motor and cognitive assessments have shown disease-related change in early HD but still lack sensitivity in premanifest cohorts. Nevertheless, functional readouts are essential to demonstrate clinical benefit.

- Structural imaging measures such as striatal atrophy show the largest effect sizes both cross-sectionally and longitudinally, and have the potential to track disease progression even in the premanifest period.

- Functional MRI and MRS are also sensitive for detecting change, but have not yet been well-validated longitudinally.

- PET imaging is quantitative and shows sensitivity to early premanifest disease, and may be useful longitudinally, though has the disadvantage of being expensive and complex.

- Biochemical assays of relevant molecules are highly desirable since they may provide more direct reflection of disease mechanisms. Such measures have not been fully validated and future work will focus on their development, in particular assessment of mutant huntingtin itself.

- A range of biomarkers with potential for use in clinical trials have been identified, but selection of the most appropriate measure will depend on the study cohort, time interval and the expected mechanism of therapeutic intervention.

- HD may provide a model for studying biomarkers and experimental therapeutics relevant to other neurodegenerative diseases

Introduction 
Huntington disease (HD) is caused by a CAG repeat expansion in the huntingtin (HTT) gene on chromosome 4, which codes for polyglutamine in the huntingtin protein. Above a threshold of about 35 or more repeats, the age of onset is inversely proportional to the length of the expansion with variable age-dependent penetrance between 36 and 39 repeats, but full penetrance at 40 or greater CAG repeats. . In addition, it has been suggested that there may be subtle abnormalities, possibly constituting an endophenotype, in the rare individuals who have repeat lengths in the 27-35 range (Squitieri and Jankovic 2012; Seong et al 2005)). HD classically manifests with a triad of signs and symptoms, including motor, cognitive and behavioural features. ${ }^{1,2}$ According to the current criteria, onset is defined as the point when a person who carries a CAG-expanded HTT allele develops "the unequivocal presence of an otherwise unexplained extrapyramidal movement disorder (for example, chorea, dystonia, bradykinesia, rigidity). ${ }^{3,4}$ We add the presence of cognitive disorder as characteristic of HD, and an important contributor to disability. Emotional disorders and personality changes are common and may be a cause of distress, but are not universal, and seem not to progress steadily as do the motor and cognitive changes.

How we define terms such as 'disease' and 'disability', and how we draw the line between 'normal' and 'abnormal', has long been a point of discussion not only in HD research, but also in the wider fields of medicine, public health, and disability studies. These distinctions have cultural and social as well as biological dimensions. The slow progression of changes initiated by the CAG-expanded HTT allele can be usefully considered in the context of recent disability theory. From this perspective, what is currently considered as 'premanifest' and 'earlystage HD' is a period of increasing impairments (biologically-based limitations or losses) with environmentally relative disabilities (that is, disadvantage related to the social environment; for example, the inability to drive in a suburban or rural environment, where driving is important for full independence. The prospect of clinical trials for HD increases the need for useful biological benchmarks. Ironically, the closer attention to measurement in the premanifest period also risks enlarging the category of the so-called 'pathological' through more-refined ways of measuring difference, thereby potentially increasing stigmatization and the psychological burden for people at risk. On the other hand, a diagnosis of disease may have some social benefits, conferring legitimacy on symptoms, and opening access to services.

In this Review, we begin by outlining the natural history of HD, mapping the emergence of motor, cognitive and emotional disorders. We review the aspects of the disease biology of HD relevant to biomarker development. We then go on to an integrative discussion of the current status of biomarker validation in $\mathrm{HD}$, and the prospects for incorporating these biomarkers into future clinical trials. Biomarkers (Box 1) for HD (Weir et al 2011) could aid both cross-sectional assessments and longitudinal monitoring in clinical trials. Cross-sectionally, biomarkers may assist in participant selection and stratification, and statistical covariance for higher power to detect treatment effects. For biomarkers to be useful longitudinally, they must show consistent changes with progression of the disorder, and should predict some aspects of clinical progression. They must also be responsive to therapeutics. Ideally, a biomarker will be close enough to the disease process and sufficiently predictive of future progression that it can be used as a 'surrogate marker' (Box 1).

The course of HD can be divided into 'premanifest' and 'manifest' periods (Figure 1). The premanifest period can be further subdivided into a period when individuals are not distinguishable clinically from controls ('presymptomatic'), usually up to 10-15 years before onset. Patients may then enter the 'prodromal' period, which is characterized by subtle motor, cognitive and behavioural changes. Once motor and cognitive signs and symptoms begin, they progress inexorably over the course of the illness, which-with the exception of late-onset cases, who may die of other causes-is uniformly fatal. 
The Unified HD Rating Scale (UHDRS) is currently the most commonly used clinical and research tool for the assessment of HD. This scale includes motor, cognitive, behavioural, emotional and functional components. The clinical assessment of premanifest individuals currently includes a 'diagnostic confidence score' subscale of the UHDRS, which scores the motor examination according to the clinician's belief that the motor signs represent HD, from 0 (no motor abnormalities suggestive of HD) to 4 (motor abnormalities $\geq 99 \%$ likely to be due to HD) ${ }^{3,7,8}$ A patient who receives a score of 4 on this scale for the first time, when assessed by an expert rater, is said to have experienced 'motor onset'. The advantage of this model is that, amid the considerable clinical phenotypic heterogeneity of the disease, motor onset emerges as one of the more robust and consistently agreed disease features. ${ }^{3}$ However, the diagnostic confidence score involves subjective assessment of ambiguous probabilities, and the concept of motor onset, or 'phenoconversion', especially if interpreted simplistically, may suggest a false dichotomy between sick and well, obscuring the fact that disease onset is really a process that occurs gradually over years or even decades.

The manifest HD period is sometimes divided into five stages. ${ }^{7,8}$ However, these stages are purely descriptive characterizations based on continuously changing functional capacity rather than on biology. This situation contrasts with many other diseases, such as cancer, in which staging relates to biological events with specific implications for prognosis and treatment. For instance, staging systems for breast or colon cancer are based on events such as conversion of cells to unchecked growth, penetration of the lamina propria, dissemination to lymph nodes, and metastasis to distant locations. These events critically influence prognosis, choice of treatments, and response to those treatments. Without such biological events to determine staging in HD, we think it simpler to divide HD into three broad phases: 'early' (patients are generally still active in most areas of functioning, and are often still working or driving), 'moderate' (patients become unable to perform complex functions such as work, driving or shopping independently, but still take care of activities of daily living [ADLs] and simple household tasks), and 'late' stages (patients can no longer take care of ADLs without help).

The systematic study of HD, leading to the identification of the HTT gene, began with the seminal and continuing study of the condition in a very large pedigree in Venezuela. ${ }^{15,16}$ Subsequently, HD research has benefited from several longitudinal single-centre and multicentre studies. PREDICT-HD ${ }^{9}$ is a large multicentre study with a total of about 800 premanifest HD cases and 200 control individuals, studied by use of clinical, neuropsychological and imaging measures for up to 10 years. TRACK-HD has studied 360 individuals (120 premanifest HD cases stratified by time to predicted onset, 120 early-stage patients, and 120 matched controls), with extensive annual assessments involving imaging and clinical measures. ${ }^{10-13}$ Figure 2 shows the 36 -month longitudinal data from TRACK-HD. REGISTRY is the largest multicentre study to date, with over 10,000 participants from 16 countries. ${ }^{14} \mathrm{~A}$ singlesite study at Johns Hopkins has followed HD families clinically for over 30 years, with some neuropsychology and imaging, and in many cases has followed individuals through the late stages of the disease to autopsy and neuropathological diagnosis (Rosenblatt et al 2004).

\section{The CAP score}

The age of clinical onset in HD is highly variable (with a mean of $\sim 45$ years), but is strongly influenced by the length of the CAG trinucleotide expansion within the HTT gene. ${ }^{17}$ The influence of CAG repeat length on rate of disease progression is less strong but still significant. ${ }^{18}$ To estimate the progression of HD pathology as a function of CAG repeat length and time of exposure to the effects of the expansion, a variable of the form AGE $\times(C A G-L)-$ where AGE is the current age of the individual, CAG is the repeat length, and $L$ is a constantwas first proposed by Penney et al. in $1997 .^{19}$ The authors showed that an index of this form was a good predictor of striatal pathology in the brains of HD patients at autopsy. 
The terms 'disease burden' and 'genetic burden' have been used to designate the Penney et al. version of this statistic, but we prefer the more neutral 'CAG-age product' (CAP). A form of a CAP score was used in the TRACK-HD study as a premanifest HD entry criterion, ${ }^{10}$ and the PREDICT-HD study uses a CAP score at entry to the study to distinguish among patients predicted to be close to, middle, or far from predicted onset at study entry. ${ }^{20}$ For the purposes of this Review, we use a standardized CAP score derived from convergent evidence from several large HD data sources (see Box 2 for derivation of this score). This score provides an index of the length and severity of the individual's exposure to the effects of the mutant HTT gene, which is useful for conveying longitudinal data from cohorts of patients with a range of ages and CAG repeat lengths.

In Figure 3, we plot clinical measures from TRACK-HD against the CAP score, and in Figure 4 we plot a variety of clinical measures from the combined data sets of COHORT and REGISTRY against the CAP score. ${ }^{14,21,22}$ One question raised by these data is whether there is an acceleration of changes in clinical measures around the time of onset of manifest HD. This issue will need more study in additional data sets, or in current data sets with moresophisticated models.

\section{Motor disorder}

The motor disorder of HD can be divided into two broad components. The first component consists of involuntary movements, especially chorea. Chorea is most prominent with adultonset or late-onset HD, begins early in the course of the disease, and gives HD its characteristic clinical appearance. The second component involves impairment of voluntary movements, and includes incoordination, bradykinesia and rigidity. This component tends to predominate in earlier-onset HD (including juvenile HD, which is quite rare) and in the late stages of the more common adult-onset HD, progresses more steadily than chorea, ${ }^{23}$ and also correlates with functional disability better than does chorea. ${ }^{18}$

Clinical assessment of the motor deficits in HD often uses the Unified Huntington's Disease Rating Scale Total Motor Score (UHDRS-TMS). ${ }^{3}$ The Hopkins study for many years used the Quantitative Neurological Examination (QNE), ${ }^{24}$ a precursor to the UHDRS with different items but similar scoring. The UHDRS motor scale, like the QNE, has ratings for items including eye movements, speech, chorea, dystonia, rapid alternating movements, bradykinesia, and gait. Scores on the UHDRS motor scale range from 0-124. Subtle motor changes begin years prior to diagnosable HD, and by the time that motor scores reach 15-20, clinicians usually feel confident enough to assign a diagnostic confidence score of 4 , indicating manifest HD.

Several measures have been developed to further quantify motor dysfunction. Simple and easily quantifiable measures of motor function can be derived from tapping on a computer keyboard; ${ }^{9}$ speed and consistency of tapping represent a simple means to quantify motor performance. More-complex and quantified metronome-paced tapping tests can improve quantification. ${ }^{25}$ Specialized force-transducer-based measures can also be used to quantify motor performance, as in the quantitative motor (Q-Motor) battery used in TRACK-HD. ${ }^{12}$ Finger tapping (digitomotography) was used to assess disease progression in all subgroups of the TRACK-HD study across 2 and 3 years. ${ }^{12,26}$ Tongue force variability and grip force variability have also been used to quantify motor features in manifest ${ }^{26-28}$ and premanifest ${ }^{26} \mathrm{HD}^{29} \mathrm{Q}$ Motor assessments can potentially be standardized across centres; they can be administered by technical assistants and may be applied repeatedly within a study, although they require specialized equipment, and have not been compared directly with simpler keyboard-based measures.

\section{Cognitive disorder}


Cognitive impairments emerge 9-15 years before diagnosis of $\mathrm{HD},{ }^{31}$ and progression of cognitive decline is gradual. In early manifest $\mathrm{HD}$, significant rates of decline are detectable over 12 months in a subset of cognitive tests, ${ }^{11}$ and more broadly after 24 months, ${ }^{32}$ whereas in premanifest HD, significant rates of cognitive decline are detectable across 36 months, and only in those individuals estimated to be about 10 years or less from diagnosis. ${ }^{13}$ Although cognitive decline in HD always occurs, individuals vary with respect to how the cognitive disorder manifests. Some evidence indicates that various aspects of cognition decline at different points in the disease course, ${ }^{33}$ although this variability might be partly explained by the fact that measures of some aspects of cognition, such as psychomotor slowing, are more sensitive than are other aspects of cognition, such as executive function. Several of the frequently used 'cognitive' tests (see below) have a substantial motor component.

The profile of cognitive decline in HD bears similarities to other disorders associated with striatal-subcortical brain pathology (for example, vascular dementia and Parkinson disease), but it differs from Alzheimer disease. ${ }^{34}$ Cognitive deficits in HD include cognitive slowing, as well as decreased attention, mental flexibility, planning, visuospatial functions and emotion recognition. ${ }^{31,32,34}$ Learning and retrieval of new information are impaired but, in contrast to Alzheimer disease, rapid forgetting is not as pronounced, ${ }^{35}$ and language is relatively preserved. Many cognitive deficits in HD occur at the intersection between cognitive and psychiatric realms of function, including problems with initiation, lack of awareness of deficits, and disinhibition. ${ }^{36}$ Thus, a typical picture of HD that emerges over time is that of social disengagement, low conversational participation, and slowed mentation, sometimes overlaid with lack of awareness of deficits and impulsivity.

The number of cross-sectional HD studies far outstrips the number of longitudinal studies, making rates of progression in different aspects of cognition or at different points in disease progression difficult to ascertain. However, in the TRACK-HD study, ten of 12 cognitive outcomes showed evidence of deterioration in early HD (Tabrizi, Scahill et al. 2011; Tabrizi, Reilmann et al. 2012; Tabrizi, Scahill et al. 2013). The greatest sensitivity to progression was in the Symbol Digit Modalities Test (visual attention and psychomotor speed), the Circle Tracing Test (visuomotor and spatial integration and transformation), and the Stroop Word Reading Test (psychomotor speed within the spoken context), with effect sizes (compared with controls) of up to 1.00 (95\% Cl 0.70-1.30). By contrast, in relatively late premanifest HD, a sample of 117 participants showed little evidence of detectable deterioration across 24 months. Many of the tests with the largest effect sizes cross-sectionally, as well as great change longitudinally, have a substantial motor or psychomotor component, emphasizing the close relationship between motor and cognitive features of $\mathrm{HD}$, both of which are presumably linked to cortical-basal ganglial circuits.

\section{Emotional disorders}

The emotional features of HD are more variable than are the motor or cognitive features. Depression is common, with depressive symptoms reported in over half of patients. ${ }^{37}$ Major depression in HD resembles depression in individuals without HD, and is treated similarly. ${ }^{38}$ Irritability is frequently present in $\mathrm{HD}$, and might be an early symptom. Apathy is a characteristic and disabling feature of the disorder, is present in most individuals at least by later stages of the disease, and tends to worsen with time. ${ }^{37}$ Strikingly, recent data from TRACK-HD indicate that a significant increase in apathy can be detected even in premanifest individuals over 36 monthsthis was the most striking single psychiatric indicator that demonstrated clear longitudinal progression. ${ }^{13}$ In early HD, baseline apathy scores were a significant baseline predictor of functional decline, and neuropsychiatric symptoms associated with frontal lobe function, such as affect, irritability and apathy, were significantly associated with functional decline in early HD. ${ }^{13}$

\section{Biomarkers for HD}




\section{Relevant biology of $H D$}

Many pathogenic mechanisms have been hypothesized for HD, but some are likely to be more relevant than others for biomarker development (Figure 5). HD is potentially a good model for development of biomarkers of direct relevance to pathogenesis, since it is caused by a single gene mutation and has an increasingly well-understood pathogenic pathway. A great need exists for target engagement biomarkers; however, they tend to be treatment-specific, and will not be the focus of this Review. Most attention in the past has focused on the CNS, but it is becoming clear that some peripheral tissues are also affected in HD. Consequently, peripheral biomarkers, such as inflammation, hold somepromise. ${ }^{39,119,120,131}$

Some of the earliest steps in the pathogenic cascade of HD include misfolding of huntingtin to a $\beta$-sheet structure ${ }^{40}$ and post-translational alterations, such as cleavage or altered phosphorylation. Specific antibodies could be developed to monitor these events. The mutant huntingtin protein has many effects in cells, including abnormalities in cellular proteostasis mechanisms, for which reporters might be available. ${ }^{41}$ The mutant protein can enter the nucleus and alter gene transcription ${ }^{42}$ the consequences of which could, conceivably, be measured. Mutant huntingtin can also affect cellular metabolism; in particular, mitochondrial function, which may lead to the production of abnormal metabolites and markers of oxidative stress. ${ }^{43}$

Age of onset and rate of progression of $\mathrm{HD}$ are both likely to be influenced by environmental and genetic modifiers. ${ }^{16,44} \mathrm{CAG}$ repeat length explains about 50 -to $70 \%$ of the variance of age of motor onset, and the residual variance has a heritability of $>.50$ (Gusella and MacDonald, 2006).

Thus far the attempts to find genetic factors other than the CAG repeat length that modify age of onset by examining the HD locus (Lee et al, 2012) or specific candidate genes (Ramos et al, 2012) or by genome wide linkage analyses (Gayan et al, 2008), have yielded negative results, or intriguing but inconsistent leads. Novel and robust genetic modifiers will, hopefully, emerge from new approaches, such as using GWAS for large series of cases or applying whole genome sequencing to small pedigrees with at least two affected individuals in different generations (Roach et al, 2010). Additional modifiers may emerge from careful examination of rare cases of $\mathrm{HD}$ that appear to develop with repeat lengths below the canonical threshold of 36 CAG triplets (Squiteri and Jankovic 2012). Finding genetic modifiers may provide leads to biomarkers.

Neuronal death is the hallmark of $\mathrm{HD}$, but neuronal dysfunction manifesting in clinical features probably occurs prior to actual cell death. Chorea has been suggested to reflect neuronal dysfunction, ${ }^{45}$ while motor impairment (bradykinesia/fine motor dysfunction) seems to be best correlated with neuronal cell death. This idea would be consistent with the observation that chorea tends to predominate early in the disease course while motor impairment supervenes later in the course. Supporting this hypothesis, motor impairment-but not choreahas been found to correlate with both the Vonsattel score (a measure of neuropathological severity) and loss of neurons as determined by stereology in postmortem striatum. ${ }^{46}$

Evidence for neuronal dysfunction, including synaptic dysfunction, is plentiful in animal models of $\mathrm{HD},{ }^{47}$ and evidence that such dysfunction can be reversible comes from both conditional knockout models ${ }^{48}$ and nucleotide-based gene silencing in mice ${ }^{49,50}$ Reversal of dysfunction seems possible even to the extent that reversal of both histopathological and neurological abnormalities is seen when production of mutant huntingtin is reduced. Thus, biomarkers relating to both neuronal dysfunction and neuronal cell death are likely to be important.

Another important issue relates to cell-autonomous versus cell-interaction mechanisms in HD pathogenesis. Mutant huntingtin is likely to have cell-autonomous toxic effects, but there may also be elements of cell interaction, which could be mediated in several different ways, 
including excitotoxicity, spread of abnormal mutant huntingtin from cell to cell in a prion-like fashion, ${ }^{51}$ and loss of trophic support from brain-derived neurotrophic factor or other trophic molecules. Whatever the biological mechanism, the implication is that localized changes might be propagated in a topographic manner (Figure 6), which could have profound implications for the design of therapeutic interventions, especially those involving localized huntingtin lowering.

\section{MRI methods}

Macrostructural brain imaging

To date, structural imaging has been the source of the most robust biomarkers for HD (Georgiou-Karistianis et al 2013). Structural MRI methodologies have demonstrated strong cross-sectional and longitudinal changes in volumes of the striatum, in both premanifest and manifest HD. ${ }^{10,52-60}$ Large longitudinal studies (PREDICT-HD and TRACK-HD) have shown significantly faster rates of decline in striatal volume in premanifest and manifest HD individuals, compared with age-matched controls, even in those individuals who are $>15$ years from estimated onset of diagnosable signs. ${ }^{61,62}$ Studies using raw volumes to calculate longitudinal change suggest that once atrophy begins, the rate remains fairly constant, and rate is significantly faster in those with higher CAG repeat lengths. ${ }^{52,61,62}$

Other regions, such as the globus pallidus, thalamus and hippocampus, also undergo atrophy, though less attention has been paid to these structures. Cross-sectional and longitudinal studies indicate that the magnitude of volume reduction is smaller in these regions than in the striatum $61,63,132$

Cortical grey matter atrophy occurs later than striatal atrophy in premanifest $\mathrm{HD},{ }^{61}$ and is less dramatic than striatal atrophy in both manifest and premanifest stages of disease. ${ }^{10,64}$ Results from cross-sectional studies differ regarding specific areas of cortical involvement (Rosas et al 2008; Aylward et al 2011; Nopoulos et al 2011). Longitudinal data from PREDICT-HD suggest that rates of change in cortical volume do not distinguish individuals with premanifest HD from controls. ${ }^{61}$ Longitudinal studies in manifest HD indicate significant change over 1-2-year periods, ${ }^{62}$ and faster rates of change as compared with controls. ${ }^{65}$

White matter volume is significantly reduced long before motor onset in $H D,{ }^{10,61,63,66-68}$ and atrophy continues into the manifest period. ${ }^{10,64,69}$ Longitudinal studies show significant atrophy over 1-2-year periods in premanifest $\mathrm{HD}^{61,62}$ and early manifest $\mathrm{HD}$. $^{11,65}$ Using Statistical Parametric Mapping methodology, the TRACK-HD group ${ }^{11}$ found that the most prominent changes in white matter occurred around the striatum and within the corpus callosum and posterior white matter tracts. Longitudinal atrophy of the corpus callosum in both premanifest and early HD cohorts has been confirmed by a recent volumetric study (Crawford et al in press). Aylward et al., using lobular regions of white matter, found the greatest volumetric change to reside in the frontal lobe. ${ }^{61,133}$

Changes in subcortical structures can also be detected using shape analysis (van den Bogard et al 2011; Younes et al 2012). This may be more sensitive than volumetric analysis and gives additional information about which subportions of brain regions may be affected.

\section{Microstructural brain imaging}

Diffusion tensor imaging (DTI) has revealed abnormalities in neuronal fibre orientation and integrity in both white matter and subcortical grey matter structures in both premanifest ${ }^{70-73}$ and manifest ${ }^{58,60,71,74-79} \mathrm{HD}$. In white matter, the greatest differences are generally found in the corpus callosum. As yet it is not established which processes contribute to volumetric loss in this structure, for example a reduction in neuronal density and/or demyelination, but recent advances in diffusion imaging are likely to further elucidate relevant mechanisms. Abnormalities in the cortico-cortico fibers in corpus callosum could result in cortical "disconnection" effects (Rosas et al 2009). 
Several studies have shown increased fractional anisotropy (or reduced diffusivity) in the basal ganglia-in particular, the putamen-in manifest and premanifest HD, ${ }^{58,60,71,72,74,77,79}$ with less-consistent findings in the globus pallidus and caudate before diagnosis. The interpretation of increased fractional anisotropy is uncertain. This parameter has been proposed to reflect the microstructure and organization of fibre tracts, but another possibility is that as neurons die, white matter tracts passing through are proportionately over-represented, resulting in increased fractional anisotropy. Other measures from DTI, including mean diffusivity, and radial and axial diffusivity, have also been found to be abnormal in HD. ${ }^{60,76}$

\section{Functional and chemical MRI}

Imaging methods that probe functional and metabolic disturbances might be especially useful early in the HD course, perhaps even before structural changes begin, and could be more responsive to therapeutic interventions compared with structural imaging measures

Functional MRI (fMRI) incorporating blood oxygen level-dependent (BOLD) contrast can provide a reflection of neuronal activity, and might be capable of identifying changes in premanifest HD even before structural brain damage. ${ }^{81-85}$ Functional changes may include regional overactivation and underactivation, which could be interpreted as signs of dysfunction, compensatory overactivity, or both. Consequently, interpretation of fMRI data can be complex It is not clear whether increases or decreases would be expected in response to therapeutic intervention. Functional connectivity can also be measured using fMRI by synchrony of the BOLD signal in spatially remote brain regions. In premanifest HD, functional connectivity has been reported to be abnormal in the motor system ${ }^{86,87}$ (Wolf et al 2012)and in systems related to cognitive processing. ${ }^{83,84,88-91}$ (Wolf et al 2008). An advantage of using functional connectivity is that it can be measured while the patient is at rest, and thus interpretation does not require consideration of differences in task performance. Nevertheless, further work validating the testretest reliability of $\mathrm{fMRI}$ data, the consistency across multiple sites, and the presence of progressive longitudinal changes is required before this technique is adopted for clinical trials.

Another promising magnetic resonance-based approach to identify early brain changes in HD is magnetic resonance spectroscopy (MRS), which has been used to identify alterations affecting $\mathrm{N}$-acetylaspartate (NAA), glutamate and glutamine. ${ }^{92-94}$ Levels of myoinositol, a marker of astrocytosis, have also recently been found to be elevated in the putamen of patients with early HD, correlating with motor dysfunction. ${ }^{94}$ Recent MRS studies using high-field-strength MRI have confirmed the results of earlier studies, especially the alterations in NAA and glutamate levels. ${ }^{95} \mathrm{MRS}$ at high field strength, with its increased signal-to-noise ratio and spectral resolution, can be used for investigation of additional metabolites, such as lactate, gluthatione and $\gamma$-aminobutyric acid, and might increase power for identification of physiological measures associated with early brain change in HD. ${ }^{95}$ Potential MRS markers of interest could subsequently may be assessed at the more-routine field strengths available with clinical MRI scanners, perhaps using spectral editing methods.

$\mathrm{MRI}$ can also be used to assay brain iron and other transition metals. Brain iron has been reported to be altered in HD (Rosas et al 2012).

\section{Clinical-imaging correlates}

Striatal volumes correlate with CAP scores and estimated time to disease onset in premanifest $\mathrm{HD},{ }^{9,57,63,96,97}$ as do white matter measures. ${ }^{63,67,98}$ Measures of motor dysfunction also strongly correlate with the volume of the striatum ${ }^{56,99,100}$ and white matter ..$^{71,100,101}$ Using digitomotography, the TRACK-HD group ${ }^{25}$ found significant correlations between motor scores and volumes of the caudate, putamen and grey matter in the right superior temporal and left precentral gyrus, as well as cortical thickness in the occipital and parietal lobes and primary motor cortex. 
Measures of cognitive function show a strong correlation with imaging variables. $55,59,63,69,100,103$ The association of corpus callosal atrophy and impairment on a visuomotor integration task in early HD suggests that a reduction in inter-hemispheric communication may have a direct impact on HD symptomatology. ${ }^{133}$ By contrast, little or no correlation is observed between structural imaging measures and psychiatric symptoms. ${ }^{63,75,100,103}$ Measures of functional capacity correlate with total grey and white matter volumes $^{64,67,104}$ and striatal volumes in manifest HD. ${ }^{99}$ Patterns of cortical thinning have been linked to other specific phenotypes that represent heterogeneity in clinical presentation and rates of progression. ${ }^{105-107}$

White matter DTI measures correlate with estimated years to HD onset, ${ }^{73}$ cognitive measures, ${ }^{71,75,78,79}$ motor measures, ${ }^{75,79}$ and apathy. ${ }^{79}$ MRS and fMRI measures have been studied less extensively, but correlations with clinical variables have been reported in very small cross-sectional studies. ${ }^{91,95}$ One $\mathrm{fMRI}$ study reported reduced activation in the dorsolateral prefrontal cortex associated with increasing working memory load in premanifest HD (Wolf et al 2007 PMID 17855375; Wolf et al 2008) and in another study, premanifest subjects who performed at a similar level to controls on a motor task employed a compensatory network in the supplementary motor area (Kloppel et al 2009 PMID 19369489). However, there are few longitudinal fMRI studies and a recent study by Wolf et al failed to show change in activation over a two year period (Wolf et al, 2012 Exp Neurol).

\section{PET methods}

Initial ${ }^{18} \mathrm{~F}$-fluorodeoxyglucose (FDG)-PET studies in patients with HD showed glucose hypometabolism in the striatum, with a suggestion of possible hypermetabolism preceding the decrease. ${ }^{109}$ A recent longitudinal study reported decline in glucose metabolism in rapidly progressing early HD patients. ${ }^{134}$ An alternative approach is to delineate a network of regions with altered metabolism. ${ }^{110,111}$ These findings show that FDG-PET, in combination with state-ofthe-art network analysis tools, may identify specific patterns of abnormal brain function in prodromal stages of HD. Patterns of metabolic alterations in preclinical HD might be used as measures for quantifying the rate of disease progression during the earliest disease phases. FDG-PET analyses might also provide suggestions of possible spread of HD-related pathology. A recent study suggested that alterations in metabolic network measures may provide useful markers for clinical trials ${ }^{135}$, although interpretation of network pattern changes and their impact on clinical performance may be complex.

\section{Prediction of key clinical changes}

For imaging measures to be candidate surrogate measures, they should ideally not only correlate with clinical measures, but also be able to predict these measures. One study has shown that striatal volumes can predict motor onset and adds predictive power beyond age and CAG repeat length alone. ${ }^{108}$ Another has study has shown that PET 2DG hypometabolism is also a predictor, though has not determined whether it adds additional predictive power beyond striatal volumes (Ciarmiello et al 2012)..

\section{Other biomarkers}

Biochemical measures of pathogenically relevant processes in accessible biofluids would be highly desirable as biomarkers for HD. Despite the ubiquitous expression of mutant huntingtin, the development of biochemical biofluid biomarkers for HD has proved challenging. ${ }^{112}$ Hypothesis-driven and 'omics' discovery approaches have yielded a multitude of candidate biomarkers, ${ }^{113,114}$ but none can be said to have been 'validated'. ${ }^{112}$ 
An example of the difficulties is 8-hydroxydeoxyguanosine (8OHdG), a product of oxidative DNA damage, which was reported to be elevated in plasma from patients with HD, and to be responsive to treatment with the antioxidant creatine. ${ }^{115}$ However, in a larger patient cohort in whom $8 \mathrm{OHdG}$ was quantified by the original laboratory, only a subtle alteration was found in patients with HD. ${ }^{116}$ In a separate study (PREQUEL), no relationship was observed between CAP scores or projected years to onset and $8 \mathrm{OHdG}$ levels, and no change in levels of this compound were seen after treatment with coenzyme $Q_{10}\left(\mathrm{CoQ}_{10}\right)$, another antioxidant. Furthermore, a rigorous, two-laboratory, blinded analysis recently reported no disease-related alterations in $8 \mathrm{OHdG}$ levels at any stage of $\mathrm{HD}$, or any significant change with longitudinal progression. ${ }^{117}$ The authors concluded that $8 \mathrm{OHdG}$ is not a useful biomarker for HD onset or progression. This work emphasizes the importance of independent replication of results, blinded sample analysis, use of multiple analytical methods, and rigorous biosample quality control for future HD biomarker studies

Future work in biofluid biomarkers is likely to focus on pathogenically relevant molecules in the cerebrospinal fluid (CSF). Unbiased omics discovery approaches in CSF have not yet identified good candidate biomarkers in HD. ${ }^{118}$ Hypothesis-driven studies will focus on functional correlates and neurobiological underpinnings of detectable changes already reported, such as immune activation, ${ }^{39,119,120}$ transcriptional dysregulation ${ }^{121}$ and cholesterol biosynthesis. ${ }^{122}$ Another possibility would be to attempt to track striatal degeneration using CSF markers such as DARPP32 or TCIP2, which would be predicted to be released into the CSF by dying medium spiny neurons.

Direct quantification of the mutant huntingtin protein itself shows promise as a pathogenically relevant marker. ${ }^{123,124}$ Mutant $\mathrm{Htt}$ levels are seen to rise with disease progression due to the accumulation of $\mathrm{N}$-terminal fragments, while $\mathrm{mHTT}$ concentration is correlated with both CAP score and brain atrophy rate, indicating potential functional relevance. ${ }^{123,124,125}$ If work that is currently underway to further improve these assays is successful, accurate quantification of mutant huntingtin in CSF might be useful, analogous to the current use of amyloid- $\beta$ peptides and tau isoforms in Alzheimer disease. ${ }^{126} \mathrm{~A}$ more valuable approach, however, might be to identify specific post-translational modifications or abnormal conformations of huntingtin that correlate with disease pathogenesis.

\section{Conclusions and future prospects}

Current clinical trials in manifest HD have required large numbers of participants (for example, 600 subjects over 5 years for the $2 \mathrm{CARE}$ study of $\mathrm{CoQ}_{10}$ ). Clinical trials in premanifest HD with clinical outcomes such as motor onset could require even larger numbers of participants, if individuals are not selected on the basis of age and CAG repeat length. Use of structural imaging biomarkers as outcome measures in clinical trials could potentially decrease the number of participants needed for efficacy trials of neuroprotective agents in HD, as the effect sizes for these structural imaging measures are so large relative to clinical measures 12,13 that sample size calculations for effectively powered studies result in smaller numbers of participants needed.

Until biomarkers can be established as surrogate markers, phase III clinical trials must have relevant clinical end points. Nevertheless, biomarkers could be extremely useful for phase II clinical trials in which the goal is to assure safety and gather initial evidence that an agent has neuroprotective properties and, thus, merits being taken to larger phase III trials with definitive clinical end points.

HD can provide a model for other neurodegenerative disorders, since it is caused by a single mutated gene and has a characteristic and well-known neuropathology and allows the study of the premanifest phase of neurodegeneration in humans, when therapeutics are most likely to be efficacious at slowing or reversing the disease. The relationship between CAG repeat length and age of onset makes it uniquely possible in studying HD to predict the age of 
onset in premanifest cases--in a fashion not possible even for the rare single gene causes of Alzheimer's disease or Parkinson's disease. Furthermore, since HD is also a protein misfolding disorder--like Parkinson's disease and Alzheimer's disease--insights from HD studies may help identify potential biomarkers for use in these disorders. In addition, the close relationship between neuronal cell death and functional disability makes correlation of neuroimaging markers with neuropathology and clinical features feasible. Striatal atrophy seems to be a remarkably stable and useful biomarker over essentially the entire course of the disease, with atrophy beginning 15 years before diagnosable onset and progressive atrophy continuing throughout the manifest period. As in Alzheimer disease, and possibly also in Parkinson disease, the changes of HD begin very early in the disease course. ${ }^{127}$ Therefore, treatment can have the goal of delaying or preventing clinical onset, as well as slowing progression of established disease. Biomarkers are likely to be most relevant for clinical trials in these early presymptomatic and prodromal periods. ${ }^{127}$

Different biomarkers might be more useful at different points in the course of HD. Steady progression of atrophy is observed in the striatum and other brain regions, and has the potential for utility over long periods. Cortical grey matter and hippocampal volumes might be more useful markers later in the disease course, especially when correlated with cognitive variables.

A number of questions remain to be answered. For example, which functional and chemical measures will be most useful and most responsive to therapeutic interventions? Do neurobiological features accelerate, resulting in biomarker changes, just prior to onset of HD? Also, which biomarkers correlate best with which clinical features of the disease at each stage in the longitudinal course? A general biological question is whether biomarkers can be expected to correlate with CAG repeat length in the HD range only, or whether the CAG repeat length even within the normal range (Seong et al 2005) is relevant.

A major-and potentially therapeutically important-question is whether imaging biomarkers can be used to trace out circuits and determine the role of cell-cell interactions (Figure 6). The combination of several MRI methods may be especially powerful. For instance it may be possible to use tract-tracing DTI and fMRI function connectivity (or PET correlation analysis) to trace changes in pathways between subregions of brain structures defined as atrophic by shape analysis. This analysis may guide therapeutics. In one scenario, if HD neuronal degeneration begins in the striatum and then progresses to other brain regions, it is conceivable that injection of RNA interference reagents into the striatum very early in the course might be sufficient to interrupt pathogenesis. Conversely, if HD pathogenesis begins in the cortex and progresses via anterograde mechanisms to the striatum, then superfusion of antisense oligonucleotides over the cortex might be sufficient to interrupt pathogenesis. If the pathology is largely cell-autonomous and occurs simultaneously in cortex and striatum, however, then severalinterventions together would be indicated. Of course, highly brainpenetrant small molecules are likely to be effective no matter which of these mechanisms is most relevant.

In summary, the validation of biomarkers for future trials of disease-modifying therapeutics to delay the onset and slow the progression of HD seems increasingly feasible. These biomarkers could be useful as outcome measures in phase II studies, and in the future might even be developed as surrogate markers for phase III studies. In turn, the methods developed for HD may be useful for development of personalized preventive therapeutics for other neurodegenerative diseases. 


\section{NEW REFS}

Aylward EH, Nopoulos PC, Ross CA, Langbehn DR, Pierson RK, Mills JA, Johnson HJ, Magnotta VA, Juhl AR, Paulsen JS; PREDICT-HD Investigators and Coordinators of Huntington Study Group. Longitudinal change in regional brain volumes in prodromal Huntington disease. J Neurol Neurosurg Psychiatry. 2011 Apr;82(4):405-10. doi: 10.1136/jnnp.2010.208264. Epub 2010 Sep 30. PubMed PMID: 20884680; PubMed Central PMCID: PMC3105627.

Ciarmiello A, Giovacchini G, Orobello S, Bruselli L, Elifani F, Squitieri F. 18F-FDG PET uptake in the pre-Huntington disease caudate affects the time-to-onset independently of CAG expansion size. Eur J Nucl Med Mol Imaging. 2012 Jun;39(6):1030-6. doi: 10.1007/s00259-0122114-z. Epub 2012 Apr 12. PubMed PMID: 22526956.

Crawford HE, Hobbs NZ, Keogh R, Langbehn DR, Frost C, Johnson H, Landwehrmeyer B, Reilmann R, Craufurd D, Stout JC, Durr A, Leavitt BR, Roos RAC, Tabrizi SJ, Scahill RI. Corpus Callosal Atrophy in Premanifest and Early Huntington's Disease. Journal of Huntington's Disease (in press).

Gayán J, Brocklebank D, Andresen JM, Alkorta-Aranburu G; US-Venezuela Collaborative Research Group, Zameel Cader M, Roberts SA, Cherny SS, Wexler NS, Cardon LR, Housman DE. Genomewide linkage scan reveals novel loci modifying age of onset of Huntington's disease in the Venezuelan HD kindreds. Genet Epidemiol. 2008 Jul;32(5):445-53.

Georgiou-Karistianis N, Scahill R, Tabrizi SJ, Squitieri F, Aylward E (2013) Structural MRI in Huntington's disease and recommendations for its potential use in clinical trials. Neurosci Biobehav Rev 37:480-490.

Gusella JF, MacDonald ME. Huntington's disease: seeing the pathogenic process through a genetic lens. Trends Biochem Sci. 2006 Sep;31(9):533-40.

Klöppel S, Draganski B, Siebner HR, Tabrizi SJ, Weiller C, Frackowiak RS. Functional compensation of motor function in pre-symptomatic Huntington's disease. Brain. 2009 Jun;132(Pt 6):1624-32. doi: 10.1093/brain/awp081. Epub 2009 Apr 15. PubMed PMID: 19369489; PubMed Central PMCID: PMC2685920.

Lee JH, Lee JM, Ramos EM, Gillis T, Mysore JS, Kishikawa S, Hadzi T, Hendricks AE, Hayden MR, Morrison PJ, Nance M, Ross CA, Margolis RL, Squitieri F, Gellera C, Gomez-Tortosa E, Ayuso C, Suchowersky O, Trent RJ, McCusker E, Novelletto A, Frontali M, Jones R, Ashizawa T, Frank S, Saint-Hilaire MH, Hersch SM, Rosas HD, Lucente D, Harrison MB, Zanko A, Abramson RK, Marder K, Sequeiros J, Landwehrmeyer GB; Registry Study of the European Huntington's Disease Network, Shoulson I; Huntington Study Group COHORT project, Myers $\mathrm{RH}$, MacDonald ME, Gusella JF. TAA repeat variation in the GRIK2 gene does not influence age at onset in Huntington's disease. Biochem Biophys Res Commun. 2012 Aug 3;424(3):4048. Epub 2012 Jul 3. PubMed PMID: 22771793; PubMed Central PMCID: PMC3752397.

Nopoulos PC, Aylward EH, Ross CA, Johnson HJ, Magnotta VA, Juhl AR, Pierson RK, Mills J, Langbehn DR, Paulsen JS; PREDICT-HD Investigators Coordinators of Huntington Study Group (HSG). Cerebral cortex structure in prodromal Huntington disease. Neurobiol Dis. 2010 Dec;40(3):544-54. doi: 10.1016/j.nbd.2010.07.014. Epub 2010 Aug 2. PubMed PMID: 20688164 ; PubMed Central PMCID: PMC2955824. 
Ramos EM, Latourelle JC, Lee JH, Gillis T, Mysore JS, Squitieri F, Di Pardo A, Di Donato S, Hayden MR, Morrison PJ, Nance M, Ross CA, Margolis RL, Gomez-Tortosa E, Ayuso C, Suchowersky O, Trent RJ, McCusker E, Novelletto A, Frontali M, Jones R, Ashizawa T, Frank S, Saint-Hilaire MH, Hersch SM, Rosas HD, Lucente D, Harrison MB, Zanko A, Marder K, Gusella JF, Lee JM, Alonso I, Sequeiros J, Myers RH, Macdonald ME. Population stratification may bias analysis of PGC-1 $\alpha$ as a modifier of age at Huntington disease motor onset. Hum Genet. 2012 Dec;131(12):1833-40. doi: 10.1007/s00439-012-1205-z. Epub 2012 Jul 25. PubMed PMID: 22825315; PubMed Central PMCID: PMC3492689.

Roach JC, Glusman G, Smit AF, Huff CD, Hubley R, Shannon PT, Rowen L, Pant KP, Goodman N, Bamshad M, Shendure J, Drmanac R, Jorde LB, Hood L and Galas DJ: Analysis of genetic inheritance in a family quartet by whole-genome sequencing. Science 328: 636-9, 2010.

Rosas HD, Chen YI, Doros G, Salat DH, Chen NK, Kwong KK, Bush A, Fox J, Hersch SM. Alterations in brain transition metals in Huntington disease: an evolving and intricate story. Arch Neurol. 2012 Jul;69(7):887-93. PubMed PMID: 22393169; PubMed Central PMCID: PMC3652228.

Rosas HD, Lee SY, Bender AC, Zaleta AK, Vangel M, Yu P, Fischl B, Pappu V, Onorato C, Cha $\mathrm{JH}$, Salat DH, Hersch SM. Altered white matter microstructure in the corpus callosum in Huntington's disease: implications for cortical "disconnection". Neuroimage. 2010 Feb 15;49(4):2995-3004. doi: 10.1016/j.neuroimage.2009.10.015. Epub 2009 Oct 19. PubMed PMID: 19850138; PubMed Central PMCID: PMC3725957.

Rosas HD, Salat DH, Lee SY, Zaleta AK, Pappu V, Fischl B, Greve D, Hevelone N, Hersch SM. Cerebral cortex and the clinical expression of Huntington's disease: complexity and heterogeneity. Brain. 2008 Apr;131(Pt 4):1057-68. doi: 10.1093/brain/awn025. Epub 2008 Mar 12. PubMed PMID: 18337273; PubMed Central PMCID: PMC2657201.

Rosenblatt A, Abbott MH, Gourley LM, Troncoso JC, Margolis RL, Brandt J, Ross CA. Predictors of neuropathological severity in 100 patients with Huntington's disease. Ann Neurol. 2003 Oct;54(4):488-93. PubMed PMID: 14520661.

Rosenblatt A, Kumar BV, Mo A, Welsh CS, Margolis RL, Ross CA. Age, CAG repeat length, and clinical progression in Huntington's disease. Mov Disord. 2012 Feb;27(2):272-6. doi: 10.1002/mds.24024. Epub 2011 Dec 15. PubMed PMID: 22173986.

Seong IS, Ivanova E, Lee JM, Choo YS, Fossale E, Anderson M, Gusella JF, Laramie JM, Myers $\mathrm{RH}$, Lesort M, MacDonald ME. HD CAG repeat implicates a dominant property of huntingtin in mitochondrial energy metabolism. Hum Mol Genet. 2005 Oct 1;14(19):2871-80. Epub 2005 Aug 22. PubMed PMID: 16115812.

Squitieri F, Jankovic J. Huntington's disease: how intermediate are intermediate repeat lengths? Mov Disord. 2012 Dec;27(14):1714-7. doi: 10.1002/mds.25172. Epub 2012 Sep 24. PubMed PMID: 23008174.

van den Bogaard SJ, Dumas EM, Ferrarini L, Milles J, van Buchem MA, van der Grond J, Roos RA. Shape analysis of subcortical nuclei in Huntington's disease, global versus local atrophy-results from the TRACK-HD study. J Neurol Sci. 2011 Aug 15;307(1-2):60-8. doi:

10.1016/j.jns.2011.05.015. Epub 2011 May 31. PubMed 
PMID: 21624624

Weir DW, Sturrock A, Leavitt BR. Development of biomarkers for Huntington's disease. Lancet Neurol. 2011 Jun;10(6):573-90. doi: 10.1016/S1474-4422(11)70070-9. Review. PubMed PMID: 21601164.

Wolf RC, Sambataro F, Vasic N, Wolf ND, Thomann PA, Saft C, Landwehrmeyer GB, Orth M. Default-mode network changes in preclinical Huntington's disease. Exp Neurol. 2012 Sep;237(1):191-8. doi: 10.1016/j.expneurol.2012.06.014. Epub 2012 Jun 25. PubMed PMID: 22742947.

Wolf RC, Sambataro F, Vasic N, Schönfeldt-Lecuona C, Ecker D, Landwehrmeyer B. Altered frontostriatal coupling in pre-manifest Huntington's disease: effects of increasing cognitive load. Eur J Neurol. 2008 Nov;15(11):1180-90. doi: 10.1111/j.1468-1331.2008.02253.x. Epub 2008 Aug 27. PubMed PMID: 18754766.

Wolf RC, Vasic N, Schönfeldt-Lecuona C, Landwehrmeyer GB, Ecker D. Dorsolateral prefrontal cortex dysfunction in presymptomatic Huntington's disease: evidence from event-related fMRI. Brain. 2007 Nov;130(Pt 11):2845-57. Epub 2007 Sep 13. PubMed PMID: 17855375.

Younes L, Ratnanather JT, Brown T, Aylward E, Nopoulos P, Johnson H, Magnotta VA, Paulsen JS, Margolis RL, Albin RL, Miller MI, Ross CA; and the PREDICT-HD Investigators and Coordinators of the Huntington Study Group. Regionally selective atrophy of subcortical structures in prodromal HD as revealed by statistical shape analysis. Hum Brain Mapp. 2012 Dec 20. doi: 10.1002/hbm.22214. [Epub ahead of print] PubMed PMID: 23281100; PubMed Central PMCID: PMC3715588.

References:

1. Huntington, G. On chorea. Med. Surg. Reporter 26, 320-321 (1872).

2. Folstein, S. E. The psychopathology of Huntington's disease. J. Nerv. Ment. Dis. 177, 645 (1989).

3. [No authors listed] Unified Huntington's disease rating scale: reliability and consistency. Huntington Study Group. Mov. Disord. 11, 136-142 (1996).

4. Hogarth, P. et al. Interrater agreement in the assessment of motor manifestations of Huntington's disease. Mov. Disord. 20, 293-297 (2005).

5. Scully, J. L. What is a disease? EMBO Rep. 5, 650-653 (2004).

6. Scully, J. L. Disability and genetics in the era of genomic medicine. Nat. Rev. Genet. 9, 797802 (2008).

7. Shoulson, I. \& Fahn, S. Huntington disease: clinical care and evaluation. Neurology 29, 1-3 (1979).

8. Shoulson, I. Huntington disease: functional capacities in patients treated with neuroleptic and antidepressant drugs. Neurology 31, 1333-1335 (1981).

9. Paulsen, J. S. et al. Detection of Huntington's disease decades before diagnosis: the Predict-HD study. J. Neurol. Neurosurg. Psychiatry 79, 874-880 (2008). 
10. Tabrizi, S. J. et al. Biological and clinical manifestations of Huntington's disease in the longitudinal TRACK-HD study: cross-sectional analysis of baseline data. Lancet Neurol. 8, 791-801 (2009).

11. Tabrizi, S. J. et al. Biological and clinical changes in premanifest and early stage Huntington's disease in the TRACK-HD study: the 12-month longitudinal analysis. Lancet Neurol. 10, 31-42 (2011).

12. Tabrizi, S. J. et al. Potential endpoints for clinical trials in premanifest and early Huntington's disease in the TRACK-HD study: analysis of 24 month observational data. Lancet Neurol. 11, $42-53$ (2012).

13. Tabrizi, S. J. et al. Predictors of phenotypic progression and disease onset in premanifest and early-stage Huntington's disease in the TRACK-HD study: analysis of 36-month observational data. Lancet Neurol. 12, 637-649 (2013).

14. Orth, M. et al. Observing Huntington's disease: the European Huntington's Disease Network's REGISTRY. J. Neurol. Neurosurg. Psychiatry 82, 1409-1412 (2010).

15. [No authors listed] A novel gene containing a trinucleotide repeat that is expanded and unstable on Huntington's disease chromosomes. The Huntington's Disease Collaborative Research Group. Cell 72, 971-983 (1993).

16. Wexler, N. S. et al. Venezuelan kindreds reveal that genetic and environmental factors modulate Huntington's disease age of onset. Proc. Natl Acad. Sci. USA 101, 34983503 (2004).

17. Langbehn, D. R., Hayden, M. R. \& Paulsen, J. S. CAG-repeat length and the age of onset in Huntington disease (HD): a review and validation study of statistical approaches. Am. J. Med. Genet. B Neuropsychiatr. Genet. 153B, 397-408 (2010).

18. Rosenblatt, A. et al. Age, CAG repeat length, and clinical progression in Huntington's disease. Mov. Disord. 27, 272-276 (2012).

19. Penney, J. B. Jr, Vonsattel, J. P., MacDonald, M. E., Gusella, J. F. \& Myers, R. H. CAG repeat number governs the development rate of pathology in Huntington's disease. Ann. Neurol. 41, 689-692 (1997).

20. Zhang, Y. et al. Indexing disease progression at study entry with individuals at-risk for Huntington disease. Am. J. Med. Genet. B Neuropsychiatr. Genet. 156B, 751-763 (2011).

21. Huntington Study Group COHORT Investigators \& Dorsey, E. Characterization of a large group of individuals with Huntington disease and their relatives enrolled in the COHORT study. PLoS ONE 7, e29522 (2012).

22. Dorsey, E. R. et al. Natural history of Huntington disease. JAMA Neurol. 70, 1520-1530 (2013).

23. Rosenblatt, A. et al. The association of CAG repeat length with clinical progression in Huntington disease. Neurology 66, 1016-1020 (2006).

24. Folstein, S. E., Jensen, B., Leigh, R. J. \& Folstein, M. F. The measurement of abnormal movement: methods developed for Huntington's disease. Neurobehav. Toxicol. Teratol. 5, 605-609 (1983).

25. Bechtel, N. et al. Tapping linked to function and structure in premanifest and symptomatic Huntington disease. Neurology 75, 2150-2160 (2010).

26. Reilmann, R. et al. Q-Motor-quantitative motor assessments: potential novel endpoints for clinical trials in pre-manifest and symptomatic Huntington's disease-36 months longitudinal results from the multicenter TRACK-HD study. Basal Ganglia 3, 67-68 (2013).

27. Reilmann, R. et al. Objective assessment of progression in Huntington's disease: a 3-year follow-up study. Neurology 57, 920-924 (2001).

28. Reilmann, R. et al. Grasping premanifest Huntington's disease-shaping new endpoints for new trials. Mov. Disord. 25, 2858-2862 (2010). 
29. Reilmann, R., Bohlen, S., Kirsten, F., Ringelstein, E. B. \& Lange, H. W. Assessment of involuntary choreatic movements in Huntington's disease-toward objective and quantitative measures. Mov. Disord. 26, 2267-2273 (2011).

31. Stout, J. C. et al. Neurocognitive signs in prodromal Huntington disease. Neuropsychology 25, 1-14 (2011).

32. Stout, J. C. et al. Evaluation of longitudinal 12 and 24 month cognitive outcomes in premanifest and early Huntington's disease. J. Neurol. Neurosurg. Psychiatry 83, 687694 (2012).

33. Snowden, J.S., Craufurd, D., Thompson, J. \& Neary, D. Psychomotor, executive, and memory function in preclinical Huntington's disease. J. Clin. Exp. Neuropsychol. 24, 133-145 (2002).

34. Peavy, G. M. et al. Cognitive and functional decline in Huntington's disease: dementia criteria revisited. Mov. Disord. 25, $1163-1169$ (2010).

35. Solomon, A. C. et al. Verbal episodic memory declines prior to diagnosis in Huntington's disease. Neuropsychologia 45, 1767-1776 (2007).

36. Duff, K. et al. "Frontal" behaviors before the diagnosis of Huntington's disease and their relationship to markers of disease progression: evidence of early lack of awareness. $J$. Neuropsychiatry and Clin. Neurosci. 22, 196-207 (2010).

37. Thompson, J. C. et al. Longitudinal evaluation of neuropsychiatric symptoms in Huntington's disease. J. Neuropsychiatry Clin. Neurosci. 24, 53-60 (2012).

38. Killoran, A. \& Biglan, K. M. Therapeutics in Huntington's disease. Curr. Treat. Options Neurol. doi:10.1007/s11940-012-0165-x.

39. Bjorkqvist, M., Wild, E. J. \& Tabrizi, S. J. Harnessing immune alterations in neurodegenerative diseases. Neuron 64, 21-24 (2009).

40. Kim, M. Beta conformation of polyglutamine track revealed by a crystal structure of Huntingtin N-terminal region with insertion of three histidine residues. Prion 7, 221-228 (2013).

41. Bence, N. F., Sampat, R. M. \& Kopito, R. R. Impairment of the ubiquitin-proteasome system by protein aggregation. Science 292, 1552-1555 (2001).

42. Seredenina, T. \& Luthi-Carter, R. What have we learned from gene expression profiles in Huntington's disease? Neurobiol. Dis. 45, 83-98 (2012).

43. Browne, S. E. et al. Oxidative damage and metabolic dysfunction in Huntington's disease: selective vulnerability of the basal ganglia. Ann. Neurol. 41, 646-653 (1997).

44. Rosenblatt, A. et al. Familial influence on age of onset among siblings with Huntington disease. Am. J. .Med. Genet. 105, 399-403 (2001).

45. Ross, C. A. \& Tabrizi, S. J. Huntington's disease: from molecular pathogenesis to clinical treatment. Lancet Neurol. 10, 83-98 (2011).

46. Guo, Z. et al. Striatal neuronal loss correlates with clinical motor impairment in Huntington's disease. Mov. Disord. 27, 1379-1386 (2012).

47. Cummings, D. M. et al. Aberrant cortical synaptic plasticity and dopaminergic dysfunction in a mouse model of Huntington's disease. Hum. Mol. Genet. 15, 2856-2868 (2006).

48. Yamamoto, A., Lucas, J. J. \& Hen, R. Reversal of neuropathology and motor dysfunction in a conditional model of Huntington's disease. Cell 101, 57-66 (2000).

49. Harper, S. Q. et al. RNA interference improves motor and neuropathological abnormalities in a Huntington's disease mouse model. Proc. Natl Acad. Sci. USA 102, 5820-5825 (2005).

50. Carroll, J. B. et al. Potent and selective antisense oligonucleotides targeting singlenucleotide polymorphisms in the Huntington disease gene / allele-specific silencing of mutant huntingtin. Mol. Ther. 19, 2178-2185 (2011).

51. Jucker, M. \& Walker, L. C. Pathogenic protein seeding in Alzheimer disease and other neurodegenerative disorders. Ann. Neurol. 70, 532-540 (2011). 
52. Aylward, E. H. et al. Longitudinal change in basal ganglia volume in patients with Huntington's disease. Neurology 48, 394-399 (1997).

53. Aylward, E. H. et al. Rate of caudate atrophy in presymptomatic and symptomatic stages of Huntington's disease. Mov. Disord. 15, 552-560 (2000).

54. Rosas, H. D.et al. Striatal volume loss in HD as measured by MRI and the influence of CAG repeat. Neurology 57, 1025-1028 (2001).

55. Peinemann, A. et al. Executive dysfunction in early stages of Huntington's disease is associated with striatal and insular atrophy: a neuropsychological and voxel-based morphometric study. J. Neurol. Sci. 239, 11-19 (2005).

56. Ruocco, H. H., Lopes-Cendes, I., Li, L. M., Santos-Silva, M. \& Cendes, F. Striatal and extrastriatal atrophy in Huntington's disease and its relationship with length of the CAG repeat. Braz. J. Med. Biol. Res. 39, 1129-1136 (2006).

57. Henley, S. M. et al. Relationship between CAG repeat length and brain volume in premanifest and early Huntington's disease. J. Neurol. 256, 203-212 (2009).

58. Vandenberghe, W., Demaerel, P., Dom, R. \& Maes, F. Diffusion-weighted versus volumetric imaging of the striatum in early symptomatic Huntington disease. J. Neurol. 256, 109-114 (2009).

59. Ginestroni, A. et al. Magnetization transfer MR imaging demonstrates degeneration of the subcortical and cortical gray matter in Huntington disease. AJNR Am. J. Neuroradiol. 31, 1807-1812 (2010).

60. Sanchez-Castaneda, C. et al. Seeking Huntington disease biomarkers by multimodal, cross-sectional basal ganglia imaging. Hum. Brain Mapp. 34, 1625-1635 (2012).

61. Aylward, E. H. et al. Longitudinal change in regional brain volumes in prodromal Huntington disease. J. Neurol. Neurosurg. Psychiatry 82, 405-410 (2011).

62. Ruocco, H. H., Bonilha, L., Li, L. M., Lopes-Cendes, I. \& Cendes, F. Longitudinal analysis of regional grey matter loss in Huntington disease: effects of the length of the expanded CAG repeat. J. Neurol. Neurosurg. Psychiatry 79, 130-135 (2008).

63. Paulsen, J. S. et al. Striatal and white matter predictors of estimated diagnosis for Huntington disease. Brain Res. Bull. 82, 201-207 (2010).

64. Rosas, H. D. et al. Evidence for more widespread cerebral pathology in early HD: an MRIbased morphometric analysis. Neurology 60, 1615-1620 (2003).

65. Hobbs, N. Z. et al. The progression of regional atrophy in premanifest and early Huntington's disease: a longitudinal voxel-based morphometry study. J. Neurol. Neurosurg. Psychiatry 81, 756-763 (2010).

66. Thieben, M. J. et al. The distribution of structural neuropathology in pre-clinical Huntington's disease. Brain 125, 1815-1828 (2002).

67. Ciarmiello, A. et al. Brain white-matter volume loss and glucose hypometabolism precede the clinical symptoms of Huntington's disease. J. Nucl. Med. 47, 215-222 (2006).

68. Paulsen, J. S. et al. Brain structure in preclinical Huntington's disease. Biol. Psychiatry 59, 57-63 (2006).

69. Beglinger, L. J. et al. White matter volume and cognitive dysfunction in early Huntington's disease. Cogn. Behav. Neurol. 18, 102-107 (2005).

70. Reading, S. A. et al. Regional white matter change in pre-symptomatic Huntington's disease: a diffusion tensor imaging study. Psychiatry Res. 140, 55-62 (2005).

71. Rosas, H. D. et al. Diffusion tensor imaging in presymptomatic and early Huntington's disease: selective white matter pathology and its relationship to clinical measures. Mov. Disord. 21, 1317-1325 (2006).

72. Klöppel, S. et al. White matter connections reflect changes in voluntary-guided saccades in pre-symptomatic Huntington's disease. Brain 131, 196-204 (2008).

73. Stoffers, D. et al. Contrasting gray and white matter changes in preclinical Huntington disease: an MRI study. Neurology 74, 1208-1216 (2010). 
74. Douaud, G. et al. In vivo evidence for the selective subcortical degeneration in Huntington's disease. Neuroimage 46, 958-966 (2009).

75. Della Nave, R. et al. Regional distribution and clinical correlates of white matter structural damage in Huntington disease: a tract-based spatial statistics study. AJNR Am. J. Neuroradiol. 31, 1675-1681 (2010).

76. Rosas, H. D. et al. Altered white matter microstructure in the corpus callosum in Huntington's disease: implications for cortical "disconnection". Neuroimage 49, 29953004 (2010).

77. Sritharan, A. et al. A longitudinal diffusion tensor imaging study in symptomatic Huntington's disease. J. Neurol. Neurosurg. Psychiatry 81, 257-262 (2010).

78. Bohanna, I. et al. Diffusion tensor imaging in Huntington's disease reveals distinct patterns of white matter degeneration associated with motor and cognitive deficits. Brain Imaging Behav. 5, 171-180 (2011).

79. Delmaire, C. et al. The structural correlates of functional deficits in early huntington's disease. Hum. Brain Mapp. 34, 2141-2153 (2012).

81. Paulsen, J. S. et al. fMRI biomarker of early neuronal dysfunction in presymptomatic Huntington's disease. AJNR Am. J. Neuroradiol. 25, 1715-1721 (2004).

82. Reading, S. A. et al. Functional brain changes in presymptomatic Huntington's disease. Ann. Neurol. 55, 879-883 (2004).

83. Paulsen, J. S. Functional imaging in Huntington's disease. Exp. Neurol. 216, 272-277 (2009).

84. Novak, M. J. et al. Altered brain mechanisms of emotion processing in pre-manifest Huntington's disease. Brain 135, 1165-1179 (2012).

85. van den Bogaard, S. J. et al. Magnetization transfer imaging in premanifest and manifest Huntington disease. AJNR. Am. J. Neuroradiol. 33, 884-889 (2012).

86. Klöppel, S. et al. Functional compensation of motor function in pre-symptomatic Huntington's disease. Brain 132, 1624-1632 (2009).

87. Unschuld, P. G. et al. Impaired cortico-striatal functional connectivity in prodromal Huntington's disease. Neurosci. Lett. 514, 204-209 (2012).

88. Mayberg, H. S. et al. Paralimbic frontal lobe hypometabolism in depression associated with Huntington's disease. Neurology 42, 1791-1797 (1992).

89. Kloppel, S. et al. Irritability in pre-clinical Huntington's disease. Neuropsychologia 48, 549557 (2010).

90. Unschuld, P. G. et al. Depressive symptoms in prodromal Huntington's disease correlate with Stroop-interference related functional connectivity in the ventromedial prefrontal cortex. Psychiatry Res. 203, 166-174 (2012).

91. Unschuld, P. G. et al. Prefrontal executive function associated coupling relates to Huntington's disease stage. Cortex 49, 2661-2673 (2013).

92. Davie, C. A., Barker, G. J., Quinn, N., Tofts, P. S. \& Miller, D. H. Proton MRS in Huntington's disease. Lancet 343, 1580 (1994).

93. Jenkins, B. G. et al. ${ }^{1} \mathrm{H}$ NMR spectroscopy studies of Huntington's disease: correlations with CAG repeat numbers. Neurology 50, 1357-1365 (1998).

94. Sturrock, A. et al. Magnetic resonance spectroscopy biomarkers in premanifest and early Huntington disease. Neurology 75, 1702-1710 (2010).

95. Unschuld, P. G. et al. Brain metabolite alterations and cognitive dysfunction in early Huntington's disease. Mov. Disord. 27, 895-902 (2012).

96. van Oostrom, J. C. et al. Striatal dopamine D2 receptors, metabolism, and volume in preclinical Huntington disease. Neurology 65, 941-943 (2005).

97. Majid, D. S. et al. Basal ganglia atrophy in prodromal Huntington's disease is detectable over one year using automated segmentation. Mov. Disord. 26, 2544-2551 (2011). 
98. Rizk-Jackson, A. et al. Evaluating imaging biomarkers for neurodegeneration in presymptomatic Huntington's disease using machine learning techniques. Neuroimage 56, 788-796 (2011).

99. van den Bogaard, S. J. et al. Shape analysis of subcortical nuclei in Huntington's disease, global versus local atrophy-results from the TRACK-HD study. J. Neurol. Sci. 307, 6068 (2011).

100. Scahill, R. I. et al. Clinical impairment in premanifest and early Huntington's disease is associated with regionally specific atrophy. Hum. Brain Mapp. 34, 519-529 (2013).

101. Jech, R. et al. Variation of selective gray and white matter atrophy in Huntington's disease. Mov. Disord. 22, 1783-1789 (2007).

103. Jurgens, C. K. et al. Basal ganglia volume and clinical correlates in 'preclinical' Huntington's disease. J. Neurol. 255, 1785-1791 (2008).

104. Squitieri, F. et al. Distinct brain volume changes correlating with clinical stage, disease progression rate, mutation size, and age at onset prediction as early biomarkers of brain atrophy in Huntington's disease. CNS Neurosci. Ther. 15, 1-11 (2009).

105. Squitieri, F. et al. Atypical movement disorders in the early stages of Huntington's disease: clinical and genetic analysis. Clin. Genet. 58, 50-56 (2000).

106. Squitieri, F. et al. Highly disabling cerebellar presentation in Huntington disease. Eur. J. Neurol. 10, 443-444 (2003).

107. Rosas, H. D. et al. Cerebral cortex and the clinical expression of Huntington's disease: complexity and heterogeneity. Brain 131, 1057-1068 (2008).

108. Aylward, E. H. et al. Striatal volume contributes to the prediction of onset of Huntington disease in incident cases. Biol. Psychiatry 71, 822-828 (2012).

109. Feigin, A. et al. Metabolic network abnormalities in early Huntington's disease: an $\left[{ }^{18}\right.$ F]FDG PET study. J. Nucl. Med. 42, 1591-1595 (2001).

110. Feigin, A. et al. Thalamic metabolism and symptom onset in preclinical Huntington's disease. Brain 130, 2858-2867 (2007).

111. Eidelberg, D. \& Surmeier, D. J. Brain networks in Huntington disease. J. Clin. Invest. 121, 484-492 (2011).

112. Weir, D. W., Sturrock, A. \& Leavitt, B. R. Development of biomarkers for Huntington's disease. Lancet Neurol. 10, 573-590 (2011).

113. Wild, E. J. \& Tabrizi, S. J. Biomarkers for Huntington's disease. Expert Opin. Med. Diagn. 2, 47-62 (2008).

114. Scahill, R. I., Wild, E. J. \& Tabrizi, S. J. Biomarkers for Huntington's disease: an update. Expert Opin. Med. Diagn. 6, 371-375 (2012).

115. Hersch, S. M. et al. Creatine in Huntington disease is safe, tolerable, bioavailable in brain and reduces serum 8OH2'dG. Neurology 66, 250-252 (2006).

116. Long, J. D., Matson, W. R., Juhl, A. R., Leavitt, B. R. \& Paulsen, J. S. 8OHdG as a marker for Huntington disease progression. Neurobiol. Dis. 46, 625-634 (2012).

117. Borowsky, B. et al. $8 \mathrm{OHdG}$ is not a biomarker for Huntington disease state or progression. Neurology 80, 1934-1941 (2013).

118. Fang, $Q$ et al. Brain-specific proteins decline in the cerebrospinal fluid of humans with Huntington disease. Mol. Cell. Proteomics 8, 451-466 (2009).

119. Wild, E., Bjorkqvist, M. \& Tabrizi, S. J. Immune markers for Huntington's disease? Expert Rev. Neurother. 8, 1779-1781 (2008).

120. Björkqvist $\mathrm{M}$ et al et al. A novel pathogenic pathway of immune activation detectable before clinical onset in Huntington's disease. J. Exp. Med. 205, 1869-1877 (2008).

121. $\mathrm{Hu}, \mathrm{Y}$. et al. Transcriptional modulator H2A histone family, member $\mathrm{Y}$ (H2AFY) marks Huntington disease activity in man and mouse. Proc. Natl Acad. Sci. USA 108, 1714117146 (2011). 
122. Leoni, V.et al. Plasma 24S-hydroxycholesterol and caudate MRI in pre-manifest and early Huntington's disease. Brain 131, 2851-2859 (2008).

123. Weiss, A. et al. Single-step detection of mutant huntingtin in animal and human tissues: a bioassay for Huntington's disease. Anal. Biochem. 395, 8-15 (2009).

124. Weiss, A. et al. Mutant huntingtin fragmentation in immune cells tracks Huntington's disease progression. J. Clin. Invest. 122, 3731-3736 (2012).

125. Moscovitch-Lopatin, M. et al. Optimization of an HTRF assay for the detection of soluble mutant huntingtin in human buffy coats: a potential biomarker in blood for Huntington disease. PLoS Curr. 2, RRN1205 (2010).

126. Blennow, K., Hampel, H., Weiner, M. \& Zetterberg, H. Cerebrospinal fluid and plasma biomarkers in Alzheimer disease. Nat. Rev. Neurol. 6, 131-144 (2010).

127. Jack, C. R. Jr et al. Tracking pathophysiological processes in Alzheimer's disease: an updated hypothetical model of dynamic biomarkers. Lancet Neurol. 12, 207-216 (2013).

128. Langbehn, D. R., Brinkman, R. R., Falush, D., Paulsen, J. S. \& Hayden, M. R. A new model for prediction of the age of onset and penetrance for Huntington's disease based on CAG length. Clin. Genet. 65, 267-277 (2004).

129. Warner, J. H. \& Hayden, M. A new model for age-at-onset in Huntington's Disease. Presented at CHDI Foundation Huntington's Disease Therapeutics Conference (Palm Springs, CA, USA, 2012).

130. Langbehn, D. et al. Improving a simple Huntington Disease burden score. Presented at World Congress on Huntington's Disease (Melbourne, Australia, 2011).

New references, need renumbering:

131. Battaglia et al., Early defect of transforming growth factor $\beta 1$ formation in Huntington's disease. J Cell Mol Med 15(3): 555-571. (2011)

132. Younes $L$ et al. Regionally selective atrophy of subcortical structures in prodromal HD as revealed by statistical shape analysis. Human Brain Mapping. doi: 10.1002/hbm.22214 [epub ahead of print] (2012)

133. Crawford HE et al. Corpus Callosal Atrophy in Premanifest and Early Huntington's Disease. Journal of Huntington's Disease (in press, 2012).

134. Shin $\mathrm{H}$. et al. Decreased Metabolism in the Cerebral Cortex in Early-Stage Huntington's Disease: A Possible Biomarker of Disease Progression? J Clin Neurol 9:21-25 (2013).

135. Tang C.C. et al. Metabolic network as a progression biomarker of premanifest Huntington's disease. J Clin Invest 123:4076-88 (2013). 


\section{Acknowledgements}

We acknowledge the contributions of the REGISTRY and COHORT study investigators for their work in collecting the data displayed in Figure 4. A complete list of the COHORT study investigators appears in The Huntington Study Group COHORT Investigators (2012) and a complete list of the REGISTRY study investigators appears in Orth, M. \& The European Huntington's Disease Network (2010). In addition we thank the European Huntington's Disease Network (EHDN), the Huntington Study Group (HSG), CHDI foundation, and HP Therapeutics for providing financial support for the data collection efforts that led to Figure 4.We thank all the study participants and their families, including the Venezuela study, The JHU study, and the TRACK-HD, REGISTRY, PREDICT-HD, and COHORT studies, who made this work possible. We thank Simon Noble, Cristina Sampaio, and Robi Blumenstein for comments and suggestions. We thank Sharon Blackburn for figure drawing.

\section{Author contributions}


Figure 1 | Natural history of clinical HD, and hypothesized changes in selected imaging biomarkers. The x-axis is the CAP score (Box 2), which enables the progression of many individuals with different CAG expansion lengths to be plotted on the same graph. [Because of "normalization," mean disease onset is at a CAP score of around 100, but there is substantial inter-individual variability, part of which is due to genetic modifiers, which are currently being sought a | Natural history. The period before the appearance of diagnosable signs and symptoms of HD is termed 'premanifest' to distinguish from the period after 'manifest' signs and symptoms are present. However, subtle signs and symptoms are usually present well before the presence of manifest HD. This period is, therefore, termed 'prodromal' HD. The period during which no signs or symptoms of HD are present is termed 'presymptomatic'. The period of manifest HD is characterized by slow progression of motor and cognitive difficulties, with chorea often prominent early but plateauing or even decreasing later, while fine motor impairment (incoordination bradykinesia and rigidity) progress more steadily. b | Hypothetical trajectory of several imaging biomarkers. The values on the $\mathrm{Y}$-axis refer to brai region volumes as a percentage of baseline volumesThis is an approximation, since the PREDICT-HD and TRACKHD studies have not followed individuals across the entire range of premanifest and manifest HD. Abbreviations: CAP, CAG-age product; HD, Huntington disease.

Figure 2 | Longitudinal data from TRACK-HD. Examples of the most robust changes in premanifest and early HD identified by the TRACK-HD study over 36 months of longitudinal study. ${ }^{12} \mathbf{a}, \mathbf{b}$ | Rates of striatal atrophy. Change in white matter volume, seen as statistical parametric maps and presented as atrophy rates by group. c | Tapping test to quantify motor function. d | Symbol Digit Modalities Test to assess visual attention and psychomotor speed. e,f | UHDRS scores total motor and functional capacity respectively. Abbreviations: HD, Huntington disease. UHDRS, Unified HD Rating Scale. PreHD-A refers to premanifest far from onset, and PreHD-B refers to premanifest close to onset. HD1 refers to early HD, HD2 later stage HD The asterisks refer to levels of significance, and the dasked lines indicate specific comparisons

Figure 3 | Change with CAP score of clinical and imaging variables from TRACK-HD. a,b | Striatal volumes. c | Tapping test to quantify motor function. d | Symbol Digit Modalities Test to assess visual attention and psychomotor speed. e,f | UHDRS scoresA colour key differentiates longitudinal changes in participants with clinical HD, preHD and observed conversion from premanifest HD (preHD) to HD ('converters') Note the very steady change in striatal volumes in all patient groups Abbreviations: CAP, CAG-age product; HD, Huntington disease. UHDRS, Unified HD Rating Scale. 
Figure 4 | Change in clinical features: data from the COHORT and REGISTRY databases. Clinical features (TMS, Chorea Score, TFC and Symbol Digit Modalities Test) are plotted against CAP scores for gene-positive individuals (HD) and against age for healthy controls. Data for patients with HD are age-adjusted (that is, expected values for healthy controls of comparable ages are subtracted from all data points). Trend lines are based on a mixed effects nonlinear model that is under development by the Model-HD project. Diagnostic status and Shoulson-Fahn stages are shown by colour coding. To improve the readability of the graphs, only baseline values for patients with HD are shown. The modelling data set excludes healthy controls with fewer than two visits, and HD patients with fewer than three visits or CAP scores $>160$. Considerable variability in clinical features is seen in both patients and controls, and the slopes of the trend lines increase around the time of expected HD diagnosis in patients with HD (CAP score about 100). The flattening of trend lines for CAP scores $>120$ might be attributable to under-representation of the sickest patients in this region. Abbreviations: CAP, CAG-age product; HD, Huntington disease; TFC, Total Functional Capacity; TMS, Total Motor Score.

Figure 5 | Schematic diagram of Huntington disease cellular pathogenesis, highlighting pathways with potential for biomarker development (red-rimmed boxes)]. In some cases, the molecule might be involved directly in pathogenesis, as with huntingtin itself, and might, therefore, also be a therapeutic target and serve as a pharmacodynamics marker as well as a marker of disease status. Abbreviations: Ac, acetyl group, P phosphate group and Su SUMO post-translational modifications BDNF, brain-derived neurotrophic factor; ROS, reactive oxygen species.

Figure 6 | Conceptual diagram of possible circuitry-related degeneration in Huntington disease. The hypothesis is that pathogenesis spreads via some form of intercellular communication, which could involve transmission of mutant huntingtin from cell to cell in a prion-like fashion. Excitotoxicity and/or loss of trophic support could also be involved in pathogenesis involving cell-cell interactions. If imaging measures can be used to track the initiation and spread of such a process, it may be possible to target huntingtin-lowering interventions to the initiating regions of the brain at the optimal time in order to minimize spread. 
Box 1 | Biomarker definitions

\section{Biological marker (biomarker)}

A characteristic that is objectively measured and evaluated as an indicator of normal biological processes, pathogenic processes, or pharmacological responses to a therapeutic intervention.

\section{Clinical end point}

A characteristic or variable that reflects how a patient feels or functions, or how long a patient survives.

\section{Surrogate end point}

A biomarker intended to substitute for a clinical end point. A clinical investigator can use epidemiological, therapeutic, pathophysiological or other scientific evidence to select a surrogate end point that is expected to predict clinical benefit or harm, or lack thereof.

\section{Criteria for biomarkers}

Can be objectively measured

Predicts clinically meaningful end points

Associated with known disease mechanisms and pathology

Predicts response to treatment

Associated with biologically relevant response to treatment

It is important to evaluate biomarkers critically in the context of the disease mechanism. For instance, some have speculated that striatal volumes could be artefactually increased by oedema or inflammation, or even conceivably by administration of large quantities of substances that add bulk to cytoplasm or cell membranes. In these instances, changes in striatal volumes would not reflect disease status, and such measurements could give unreliable or incorrect information about the disease and potential treatments. 
Box 2 | CAP score and HD progression

As used in this Review, the CAP score is defined follows: CAP $=100 \times A G E \times[(C A G-L) \div S]$, where CAG is the patient's CAG repeat length, AGE is the patient's current age at the time of observation, and $L$ and $S$ are constants. $S$ is a normalizing constant chosen so that the CAP score is approximately 100 at the patient's expected age of onset as estimated by Langbehn et al. (2004). ${ }^{128} \mathrm{~L}$ is a scaling constant that anchors CAG length approximately at the lower end of the distribution relevant to HD pathology. $L$ has been estimated at slightly different values; for example, Zhang et al. use $L=33.66,{ }^{20}$ whereas Penney et al. use $L=35.5{ }^{19}$

The graphs shown in this Review use $L=30$ and $S=627$, which are estimates obtained by a reanalysis of the data in Langbehn et al. ${ }^{128}$ presented by Warner and Hayden. ${ }^{129}$ In this respect, it is similar to measures from Langbehn et al. ${ }^{128}$ related to onset risk. The optimal value of $L$ was also found to be about 30 for correlation with a wide variety of clinical measures as reported by Langbehn et al. ${ }^{130}$ Intuitively, L might be thought of as the lower limit of the CAG lengths for which some pathological effect might be expected. Direct evidence for detectable HD pathology in the CAG range 30-35 is sparse and controversial, so the exact value of $L$ within this range might be difficult to interpret. Nevertheless, the existence of a striking threshold for pathogenesis is reflected in the equation.

Abbreviations: CAP, CAG-age product;; HD, Huntington disease. 